\title{
Response: Commentary: Greater Emotional Gain from Giving in Older Adults: Age-Related Positivity Bias in Charitable Giving
}

\author{
Pär Bjälkebring ${ }^{1 *}$, Daniel Västfjäll ${ }^{2,3}$, Stephan Dickert ${ }^{2,4}$ and Paul Slovic ${ }^{3}$ \\ ${ }^{1}$ Department of Psychology, University of Gothenburg, Gothenburg, Sweden, ${ }^{2}$ Department of Behavioural Sciences and \\ Learning, Linköping University, Linköping, Sweden, ${ }^{3}$ Decision Research, University of Oregon, Eugene, OR, USA, ${ }^{4}$ School of \\ Business and Management, Queen Mary University of London, London, UK
}

Keywords: charitable giving age, emotion, motivation, decision making

\section{A response to}

Commentary: Greater Emotional Gain from Giving in Older Adults: Age-Related Positivity Bias in Charitable Giving

by Hargis, M. B., and Oppenheimer, D. M. (2016). Front. Psychol. 7:1075. doi: 10.3389/fpsyg.2016. 01075

OPEN ACCESS

Edited by:

Shulan Hsieh,

National Cheng Kung University,

Taiwan

Reviewed by:

Joshua Oon Soo Goh,

National Taiwan University, Taiwan

${ }^{*}$ Correspondence:

Pär Bjälkebring

par.bjalkebring@psy.gu.se

Specialty section:

This article was submitted to

Cognition,

a section of the journal

Frontiers in Psychology

Received: 21 October 2016

Accepted: 16 November 2016

Published: 30 November 2016

Citation:

Bjälkebring P, Västfjäll D, Dickert S and

Slovic P (2016) Response:

Commentary: Greater Emotional Gain from Giving in Older Adults:

Age-Related Positivity Bias in

Charitable Giving.

Front. Psychol. 7:1887.

doi: 10.3389/fpsyg.2016.01887
We thank Hargis and Oppenheimer (2016) for their interesting commentary to our article (Bjälkebring et al., 2016). Age-related changes in decision making are indeed a relatively unexplored phenomenon especially when it comes to more specific decision situations such as prosocial acts.

Prosocial behaviors are distinct in the way that they feature both positive and negative emotions, moral considerations as well as other highly cognitive determinants (i.e., calculations of utility and efficacy). When it comes to the influence of age related cognitive decline on decision making earlier studies (i.e., Salthouse, 1996) most probably have overestimated this decline due to cohort differences (i.e., The Flynn Effect; Rönnlund and Nilsson, 2009) and newer longitudinal studies (i.e., Rönnlund et al., 2005; Gerstorf et al., 2011) suggest that the cognitive decline associated with normal aging does not have much functional impact until the last decade in a person's life, this is especially evident in time to death models (Thorvaldsson et al., 2008). In addition, "cognitive decline" might be too broad of a term to describe what happens during the life-span, results from the Baltimore Longitudinal Study of Aging suggest that longitudinal cognitive aging of executive and memory functions is not a uniform process but a heterogeneous one (Goh et al., 2012). However, recent research has shifted from investigating age-related cognitive decline to investigating age-related cognitive changes, for example the positivity bias seems to be connected not to cognitive decline (i.e., degradation) but to cognitive changes (i.e., motivation; Kalenzaga et al., 2016). Additionally, evidence exists that there are tangible cognitive processes that differ between older and younger adults, for example the use of gist and verbatim memory processes (Flores et al., 2016). Largely, emotional maturity processes as well as life experience seem to improve decision making throughout the lifespan and research suggest that people peak as decision makers in the second half of the lifespan (Strough et al., 2015). Interestingly, current research into risk taking has suggested that changes in risk taking could be consistent with age-related dopaminergic decline (Rutledge et al., 2016). That being said, people continue to make decisions late in life, one example being a person's final will and testament, a major consideration regarding prosocial giving. Hence, a life-span view of age related biological, cognitive, motivational, and emotional change and decline is needed. When it comes to prosocial decisions specifically, not much research have been conducted related to age related changes. However, there are some age-related differences that 
could be expected based on current theories and findings. One of these is the compassion fade, meaning that more emotions are elicited toward one victim compared to many (Västfjäll et al., 2014). Additionally, young and old could possibly differ when it comes to moral considerations, such as the valuation of lives (Dickert et al., 2012).

We agree with Hargis and Oppenheimer (2016) that the positivity bias is not the only process related to affect or the processing of affect that could possibly influence age differences in prosocial decision making. First, an aspect we do not discuss is the age-related preference for different emotions. Based on Russell's (2003) notion that preference for affect can change when arousal changes, as well as previous research on age differences in arousal preference (Kessler and Staudinger, 2009; Mogilner et al., 2011; English and Carstensen, 2014). It is expected that older adults prefer low arousal emotions when compared to high arousal emotions. In line with this older adults rated their happiness lower when it was framed as high in arousal (ecstatic), and higher when it is was framed as low in arousal (satisfied; Bjalkebring et al., 2015). Secondly, older and younger adults seem to differ in the way they regulate their emotions. As an example adults use reappraisal more often than younger adults (Gross and John, 2003). When it comes to decision making one of the most important emotions is regret. Research suggests that older and younger adults may differ in their experience, anticipation, and regulation of regret partly because the opportunity to overcome regret declines with age (Peters et al., 2011). This is illustrated by the research of (Wrosch and Heckhausen, 2002) as well as (Wrosch et al., 2005). In their studies, participants were asked to report activities that they regretted not having pursued during their lives and to indicate the amount of personal control they had on the situation at the time. Both the experience and regulation of regret differed between younger and older adults. When younger adults reported that they had personal control (internal control) over the regretted activity, it was associated with active attempts to change the regrettable behavior, and hence reduced regret as well as reduced rumination. In contrast, for older adults, internal attributions were instead associated with more intense regrets. Research have shown that older adults differ from younger adults in the use of regret regulatory strategies they use to regulate

\section{REFERENCES}

Bjälkebring, P., Västfjäll, D., Dickert, S., and Slovic, P. (2016). Greater Emotional Gain from Giving in Older Adults: Age-Related Positivity Bias in Charitable Giving. Front. Psychol. 7:846. doi: 10.3389/fpsyg.2016.00846

Bjälkebring, P., Västfjäll, D., and Johansson, B. (2013). Regulation of experienced and anticipated regret for daily decisions in younger and older adults in a Swedish one-week diary study. GeroPsych 26, 233. doi: 10.1024/1662-9647/ a000102

Bjalkebring, P., Västfjäll, D., and Johansson, B. E. (2015). Happiness and arousal: framing happiness as arousing results in lower happiness ratings for older adults. Front. Psychol. 6:706. doi: 10.3389/fpsyg.2015.00706

Dickert, S., Västfjäll, D., Kleber, J., and Slovic, P. (2012). Valuations of human lives: normative expectations and psychological mechanisms of (ir)rationality. Synthese 189, 95-105. doi: 10.1007/s11229-012-0137-4

English, T., and Carstensen, L. L. (2014). Emotional experience in the mornings and the evenings: consideration of age differences in specific their daily decision regret, this also indicates that lower negative emotions in older adults is not a consequence of declining cognitive ability but rather a consequence of older adults using emotional regulatory strategies (Bjälkebring et al., 2013).

Finally, we want to stress the importance of validating the age differences found in cross-sectional experimental studies such as our own with longitudinal studies. There are several longitudinal studies already that could possibly verify at least some of the cross-sectional findings in the literature (H70, OCTO TWIN, HRS, BETULA, Seattle Longitudinal Study, the Baltimore Longitudinal Study of Aging, etc.). In cases where longitudinal studies cannot verify the cross-sectional findings such longitudinal studies should be conducted.

Research has only scratched the surface of understanding age related changes in cognition, affect, and motivation. This provides both challenge and an opportunity for researchers to fill the gaps. The next few decades will be very interesting. We can only hope to, as the Vulcans say, "dif-tor heh smusma" or in English "live long and prosper."

\section{AUTHOR CONTRIBUTIONS}

PB drafted the manuscript, and DV, SD, and PS provided critical revisions. All authors approved the final version of the manuscript for submission.

\section{FUNDING}

The first author is funded by The Swedish Research Council Award Number 2016-00507. This research was supported by grant from the Swedish Research Council for Health, Working Life and Welfare (FORTE, previously FAS) and Centre for Aging and health-AGECAP.

\section{ACKNOWLEDGMENTS}

Special thanks to Compassion Week at Decision Research, Oregon, that made it possible for the authors to meet and discuss this manuscript. emotions by time of day. Front. Psychol. 5:185. doi: 10.3389/fpsyg.2014. 00185

Flores, C. C., Hargis, M. B., McGillivray, S., Friedman, M. C., and Castel, A. D. (2016). Gist-based memory for prices and "better buys" in younger and older adults. Memory. doi: 10.1080/09658211.2016.1197944. [Epub ahead of print].

Gerstorf, D., Ram, N., Hoppmann, C., Willis, S. L., and Schaie, K. W. (2011). Cohort differences in cognitive aging and terminal decline in the Seattle Longitudinal Study. Dev. Psychol. 47, 1026-1041. doi: 10.1037/a0023426

Goh, J. O., An, Y., and Resnick, S. M. (2012). Differential trajectories of age-related changes in components of executive and memory processes. Psychol. Aging 27, 707-719. doi: 10.1037/a0026715

Gross, J. J., and John, O. P. (2003). Individual differences in two emotion regulation processes: implications for affect, relationships, and well-being. J. Pers. Soc. Psychol. 85, 348-362. doi: 10.1037/0022-3514.85.2.348

Hargis, M. B., and Oppenheimer, D. M. (2016). Commentary: greater emotional gain from giving in older adults: age-related positivity bias in charitable giving. Front. Psychol. 7:1075. doi: 10.3389/fpsyg.2016.01075 
Kalenzaga, S., Lamidey, V., Ergis, A.-M., Clarys, D., and Piolino, P. (2016). The positivity bias in aging: motivation or degradation? Emotion 16, 602-610. doi: $10.1037 /$ emo0000170

Kessler, E.-M., and Staudinger, U. M. (2009). Affective experience in adulthood and old age: The role of affective arousal and perceived affect regulation. Psychol. Aging 24, 349-362. doi: 10.1037/a0015352

Mogilner, C., Kamvar, S. D., and Aaker, J. (2011). The shifting meaning of happiness. Soc. Psychol. Personal. Sci. 2, 395-402. doi: 10.1177/ 1948550610393987

Peters, E., Västfjäll, D., and Bjälkebring, P. (2011). “The experience and regulation of regret across the adult life span," in Emotion Regulation and Well-Being, Part 2 (Vol. s.) (New York, NY: Springer), 165-180. Available online at: http://link. springer.com/chapter/10.1007/978-1-4419-6953-8_10

Rönnlund, M., and Nilsson, L.-G. (2009). Flynn effects on sub-factors of episodic and semantic memory: parallel gains over time and the same set of determining factors. Neuropsychologia 47, 2174-2180. doi: 10.1016/j.neuropsychologia. 2008.11.007

Rönnlund, M., Nyberg, L., Bäckman, L., and Nilsson, L.-G. (2005). Stability, growth, and decline in adult life span development of declarative memory: cross-sectional and longitudinal data from a population-based study. Psychol. Aging 20, 3-18. doi: 10.1037/0882-7974.20.1.3

Russell, J. A. (2003). Core affect and the psychological construction of emotion. Psychol. Rev. 110, 145-172. doi: 10.1037/0033-295X.110.1.145

Rutledge, R. B., Smittenaar, P., Zeidman, P., Brown, H. R., Adams, R. A., Lindenberger, U., et al. (2016). Risk Taking for Potential Reward Decreases across the Lifespan. Curr. Biol. 26, 1634-1639. doi: 10.1016/j.cub.2016.05.017

Salthouse, T. A. (1996). The processing-speed theory of adult age differences in cognition. Psychol. Rev. 103, 403-428.
Strough, J., Parker, A. M., and Bruine de Bruin, W. (2015). "Understanding life-span developmental changes in decision-making competence," in Aging and Decision Making: Empirical and Applied Perspectives, eds T. Hess, J. Strough, and C. Löckenhoff (San Diego, CA: Elsevier Academic Press), 235-257.

Thorvaldsson, V., Hofer, S. M., Berg, S., Skoog, I., Sacuiu, S., and Johansson, B. (2008). Onset of terminal decline in cognitive abilities in individuals without dementia. Neurology 71, 882-887. doi: 10.1212/01.wnl.0000312379.02302.ba

Västfjäll, D., Slovic, P., Mayorga, M., and Peters, E. (2014). Compassion fade: affect and charity are greatest for a single child in need. PLOS ONE 9:e100115. doi: 10. 1371/journal.pone.0100115

Wrosch, C., Bauer, I., and Scheier, M. F. (2005). Regret and quality of life across the adult life span: the influence of disengagement and available future goals. Psychol. Aging 20, 657-670. doi: 10.1037/0882-7974.20.4.657

Wrosch, C., and Heckhausen, J. (2002). Peceived control of life regrets: good for young and bad for old adults. Psychol. Aging 17, 340-350. doi: 10.1037/08827974.17.2.340

Conflict of Interest Statement: The authors declare that the research was conducted in the absence of any commercial or financial relationships that could be construed as a potential conflict of interest.

Copyright (C) 2016 Bjälkebring, Västfjäll, Dickert and Slovic. This is an open-access article distributed under the terms of the Creative Commons Attribution License (CC $B Y)$. The use, distribution or reproduction in other forums is permitted, provided the original author(s) or licensor are credited and that the original publication in this journal is cited, in accordance with accepted academic practice. No use, distribution or reproduction is permitted which does not comply with these terms. 